lying disease. In those described by Lowenstein and Gallo ${ }^{1}$ renal deposits of amyloid persisted despite clinical remission of the nephropathy. Both our patients had spontaneous remissions of nephrotic syndrome without treatment for the underlying disease. In one the urine became protein free and in the other the proteinuria became trivial. In both the serum albumin concentration returned to normal. Yet renal biopsy specimens before and after the period of remission in case 1 showed progression of amyloid deposition. In both patients amyloidosis eventually led to chronic renal failure.

Interest grows in new treatments for amyloidosis. ${ }^{45}$ Whatever the mechanisms underlying the spontaneous fluctuations in the nephropathy in these cases their course emphasises the need for care in assessing new therapies. The low incidence of this condition imposes formidable logistic problems in organising controlled trials, but without such trials new treatments will be difficult to evaluate.

${ }^{1}$ Lowenstein, J, and Gallo, G, New England fournal of Medicine, 1970, 282, 128.

2 Triger, D R, and Joekes, A M, Quarterly fournal of Medicine, 1973, 42, 15.

${ }^{3}$ Omer, H, and Wahab, S M A, British Medical fournal, 1976, 1, 375.

${ }^{4}$ Jones, N F, Clinical Nephrology, 1976, 6, 459.

${ }^{5}$ Lyle, L R, Parker, B M, and Parker, C W, fournal of Immunology, 1974, $113,517$.

(Accepted 7 February 1978)

St Thomas's Hospital, London SE1 7EH

J MICHAEL, MB, MRCP, senior medical registra

N F JONES, MD, FRCP, consultant physician

\section{Hexapropymate self-poisoning}

Hexapropymate, a carbamate with similar pharmacological properties to meprobamate, ${ }^{12}$ is available without prescription in Belgium under the trade name Merinax. Each Merinax tablet contains $400 \mathrm{mg}$ of hexapropymate. Self-poisoning is uncommon and has not been reported in Britain. We report here a case of severe poisoning.

\section{Case report}

A 28-year-old man was admitted in October 1977 having been found unconscious in a local park. His pockets contained four empty hexapropymate packets. Each packet had contained 10400 -mg tablets. No other history was available.

He was deeply unconscious with no response to maximally painful stimuli. Corneal, gag, and cough reflexes were absent. He was hypotensive (blood pressure $75 / 0 \mathrm{~mm} \mathrm{Hg}$ ), hypothermic (rectal temperature $28^{\circ} \mathrm{C}$ ), and cyanosed. Immediate endotracheal intubation was required. An irregular pulse was noted and his electrocardiogram showed bouts of tachycardia, probably supraventricular, but with evidence of intraventricular block (see fig). He was treated with intravenous fluids, rewarming, and assisted ventilation. Gastric lavage was performed, and large amounts of vomit removed from the bronchi. His supraventricular tachycardia rapidly reverted to sinus rhythm of $100 / \mathrm{min}$ with a blood pressure of $100 / 70 \mathrm{~mm} \mathrm{Hg}$. He had signs of left lower lobe collapse, which was confirmed by chest radiographs.

Blood sugar, urea, creatinine, electrolytes, and serum amylase concentrations were normal. He was acidotic with a blood lactate of $6.9 \mathrm{mmol} / 1$

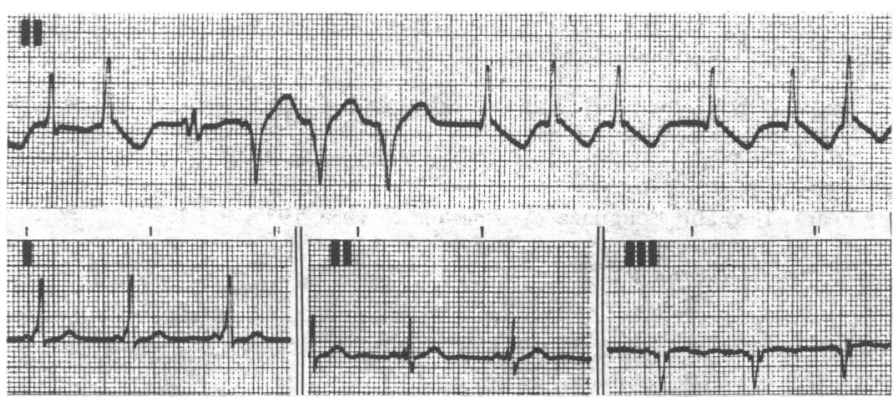

Top: electrocardiogram, standard lead II, showing tachycardia on admission. Bottom: electrocardiogram, standard leads I, II, and III, showing sinus rhythm and apparent short P-R interval due to delta waves.
$62 \cdot 1 \mathrm{mg} / 100 \mathrm{ml}$ ), arterial pH 7.053, $\mathrm{Pco}_{2} 6 \cdot 25 \mathrm{kPa}(47 \mathrm{~mm} \mathrm{Hg}), \mathrm{Po}_{2} 15 \cdot 3 \mathrm{kPa}$ $(115 \mathrm{~mm} \mathrm{Hg})$, bicarbonate $13.8 \mathrm{mmol}(\mathrm{mEq}) / \mathrm{l}$. The blood and urine contained no salicylates, barbiturates, glutethimide, or paracetamol. Urine analysis, verified against known samples of hexapropymate, showed excretions of $878 \mathrm{mg}, 197 \mathrm{mg}$, and $80 \mathrm{mg}$ of hexapropymate on the first three days respectively after admission. Electrocardiograms showed sinus rhythm, apparent short P-R intervals, delta waves, and rSR pattern in chest leads V1 and V2, suggestive of a type B Wolff-Parkinson-White syndrome (see figure). Liver function tests showed mild hepatocellular damage which gradually resolved.

His rectal temperature rose to $37^{\circ} \mathrm{C}$ over 12 hours, but he remained deeply unconscious with absent reflexes for four days. During this period erythematous and urticarial macules appeared over his legs. These may have been caused by hexapropymate or by sensitivity to ampicillin administered to combat inhalational pneumonia. Consciousness returned on the fifth day, during which he was febrile and had rigors. Blood cultures, midstream urine, and sputum were sterile. He subsequently recovered fully. $\mathrm{He}$ admitted to having taken $40400-\mathrm{mg}$ hexapropymate tablets, but denied taking any other drugs. He had arrived in this country two days before admission to hospital, having bought the tablets in Belgium.

\section{Comment}

Poisoning with about $16 \mathrm{~g}$ of hexapropymate induced deep coma in our patient and led to respiratory depression, hypothermia, inhalational pneumonia, and lactic acidosis. Prompt resuscitation and supportive measures resulted in complete recovery. The effects of hexapropymate poisoning ${ }^{3}$ seem to be similar to those of other carbamates. ${ }^{4}$ The tachyarrhythmia found on admission may have been induced by hypoxia or hypothermia. Only one episode of tachycardia was noted in 20 cases of hexapropymate poisoning reported to Brussels's poison centre. ${ }^{5}$ The effects of hexapropymate in the WolffParkinson-White syndrome have not been reported.

We thank Mr B Yeoman of the Regional Toxicology Centre, Dudley Road Hospital, Birmingham, for analysing the urine.

From 27 December 1977 Merinax (Hexapropymate) became available solely on prescription.

1 Wade, A, (editor), Martindale, The Extra Pharmacopoeia, 27th edn. London, Pharmaceutical Press, 1977.

2 Troch, E, Acta Anaesthesia Belgique, 1958, 9, 49.

3 Noirfalise, A, European fournal of Toxicology, 1971, 1, 50.

${ }^{4}$ Jenis, E H, et al, fournal of the American Medical Association, 1969, 207, 361.

${ }^{5}$ Le Centre Anti-Poisons de Bruxelles. Information on file.

(Accepted 15 February 1978)

Royal Lancaster Infirmary, Lancaster

G ROBBINS, BSC, $M B$, senior house officer in medicine

A K BROWN, MB, FRCP, consultant physician

\section{Where are the untreated depressives?}

In the course of a clinical trial of antidepressant drugs ${ }^{1}$ it proved more difficult than expected to acquire a numerically adequate series of suitable patients referred as outpatients or admissions to the specialist psychiatric services. Abandonment of a similar trial for lack of patients has been reported already, ${ }^{2}$ using selection criteria based on those of the MRC trial of treatments for depressive illness. ${ }^{3}$ The criteria for inclusion in our study ${ }^{1}$ were much less exclusive: $(a)$ the referring doctor considered the quality and degree of the patient's depressive affect indicated the use of a tricyclic antidepressant drug; $(b)$ the psychiatrist agreed on the treatment indications; $(c)$ the patient should not have been prescribed any antidepressant in the three months before referral. We have studied possible reasons for this "shortage" of depressives.

\section{Patients, methods, and results}

Experience at Crichton Royal Hospital-Twelve general practitioners who regularly referred patients to JCL were asked to refer suitable patients for the trial. In the first year from July 1974 a total of 14 patients were so referred, of whom only seven could be included in the trial. A second appeal letter was sent out and the next year yielded a further 19 referrals for the trial, of whom nine were suitable. A third letter in June 1976 resulted in only 
two more patients by the end of September 1976, giving a total over 27 months of 17 patients accepted into the trial out of a total of 35 specially referred. Of the 18 who did not fulfil the trial criteria, 16 were offered treatment: 13 were taken on, two declined, and one defaulted. Reasons for exclusion from the trial are shown in the table.

The Newcastle experience-TAK and HAMcC selected suitable patients from their high urban case load of outpatient referrals and admissions. Bu to complete the series the criterion of three months without previous antidepressant treatment could not be firmly adhered to throughout. In the nine months from January to September 197620 patients entered the trial in Newcastle upon Tyne.

Reasons for rejection of specially referred patients from the trial

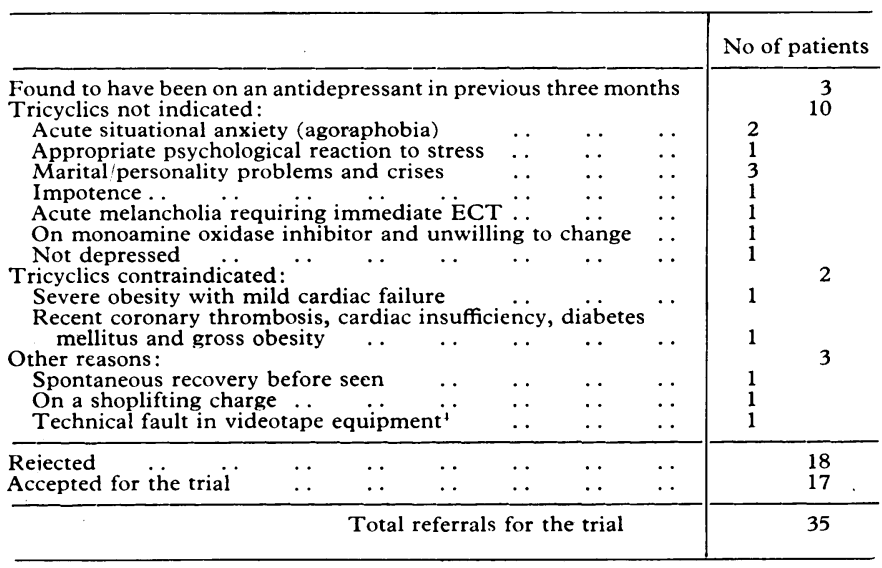

\section{Comment}

From the late 1950s through the '60s the treatment of depressive illness by psychiatrists was at its peak. Thereafter the numbers of depressed patients under care and treatment by psychiatrists began to decline. At first, probably as a result of successful treatment as outpatients, the number of patients with depression in hospitals fell by $10 \%$ in England and Wales between 1963 and 1971.

At the Crichton Royal between 1968 and 1976 outpatient referrals of patients given one of the ICD depressive diagnoses fell by $47 \%$, while admissions for depression fell by $31 \%$. In Newcastle, at $\mathrm{S}$ Nicholas Hospital, over the same eight years, admissions for depression fell by $22 \%$. The reduction in referrals with depressive disorders is probably a combined effect of the increasing use of antidepressants by general practitioners and a reduction of re-referrals of recurrent manic depressive psychoses owing to the increasing use of lithium in secondary prevention.

This observation has considerable implications for clinical research in psychiatry when, as in our experience, a clinician can now attract only 10 suitable untreated depressives in a year for a drug trial with broad selection criteria. Were Leff's reasonable case for eliminating polar prognostic groups to be adopted, ${ }^{5}$ the single-handed clinician could well take 10 years or more to collect two series of 25 depressed patients adequate for a drug effect comparison. The lesson is clear: psychiatrists can henceforth pursue drug trials in depressive illness only under two conditions: firstly, in collaborative multicentre investigations; secondly, by moving out of the wards and outpatient departments and attaching to one or more general practices, for it is here that the untreated depressive now presents.

${ }^{1}$ McClelland, H A, Kerr, T A, and Little, J C, British fournal of Clinical Pharmacology, 1977, 4, 233S.

2 Blackwell, B, and Shepherd, M, Lancet, 1967, 2, 819.

3 Medical Research Council, British Medical fournal, 1965, 1, 881.

4 Little, J C, McClelland, H A, and Kerr, T A, British fournal of Clinical Pharmacology, 1977, 4, 227S.

5 Leff, J, British Medical fournal, 1973, 4, 156.

(Accepted 23 February 1978)

Department of Clinical Research, Crichton Royal, Dumfries

J C LITTLE, MD, FRCP, director and consultant psychiatrist

St Nicholas Hospital, Gosforth, Newcastle upon Tyne

T A KERR, MD, MRCPSYCH, consultant psychiatrist

H A MCCLELLAND, FRCP, FRCPSYCH, consultant psychiatrist

\section{Drug dependence caused by dihydrocodeine}

The development of tolerance and physical dependence with repeated use is a characteristic feature of all the opiate and opioid drugs, and $\mathbb{D}$ the possibility of developing psychological dependence on their.. effects is one of the major limitations of their clinical use.

Eddy et $a l^{1}$ reported that dihydrocodeine was an effective analgesic, which, however, never seemed to attain the potency of morphine. At its optimal dose of $30 \mathrm{mg}$ little respiratory depression occurred and $\overline{0}$ there were no other side effects of significance other than drowsiness. $\overline{\bar{D}}$ Increasing the dose to $60 \mathrm{mg}$ increased the analgesia only slightly but $\vec{\nabla}$ did cause the appearance of morphine-like side effects and respiratory $\varrho$ depression. It is extremely likely that dihydrocodeine is metabolised \& in a similar fashion to codeine-that is, by $\mathrm{N}$-demethylation, $\overrightarrow{0}$ o-demethylation, and conjugation. Codeine itself can undergo d-demethylation to morphine. Although this is usually a minor path- $\vec{\omega}$ way, with increased ingestion it does become important. In addition, possibly o-demethylation might be a more favoured pathway in those who become addicted to dihydrocodeine.

\section{Case reports}

Case 1-A 30-year-old housewife who complained of headache was given three months' supply of dihydrocodeine. She returned to her doctor after $\mathcal{G}$ two months asking for a further supply. Over six months she had increased her dose to $60 \mathrm{mg}$ four or five times a day, from one tablet taken as necessary originally. She was continually drowsy and lost her job. In a fit of $\frac{\mathrm{O}}{\supset}$ depression she took 30 dihydrocodeine tablets and was admitted to hospital ב with constricted pupils. Two days later she began a course of psychiatric $\vec{V}$ rehabilitation.

Case 2-A 49-year-old company director who had pain at the site of an old $\bar{\Xi}$ thoracotomy wound was given dihydrocodeine, $30 \mathrm{mg}$ twice daily. Six months later he had increased the dosage to $60 \mathrm{mg}$ four times a day. He $\vec{c}$ admitted to his general practitioner one year later that he had irritability, sweating, anxiety, palpitations, and insomnia on withdrawal of the dihydrocodeine. Despite attempts to wean him from the drug he has continued to take $60 \mathrm{mg}$ three times a day and $120 \mathrm{mg}$ at night for three years.

Case 3-A 23-year-old engineering student was given a supply of dihydrocodeine tablets, $30 \mathrm{mg}$ to be taken as required because of a strained muscle. At vacation time he was given three months' supply, and after this was over he was noticeably drowsy with constricted pupils. On questioning he admitted that he found taking dihydrocodeine pleasurable. On drug withdrawal he became restless and irritable and could not sleep. At that time he was taking $90 \mathrm{mg}$ four times a day.

Case 4-A 26-year-old artist with a history of drug misuse had started taking dihydrocodeine, $60 \mathrm{mg}$ at night time, because it facilitated sleep. After four months he was taking $90 \mathrm{mg}$ four times a day for the agreeably drowsy sensation it caused. At this time he developed signs of acute peptic ulceration. His pupils were constricted and he was severely constipated. He was referred to a psychiatrist.

Case 5-A 50-year-old insurance broker with severe osteoarthritis was $\frac{0}{3}$ given dihydrocodeine, $60 \mathrm{mg}$ thrice daily. He felt more relaxed after taking the tablets, and the dose before bed time helped him to sleep. After four months he had increased his dose to $90 \mathrm{mg}$ four times daily and he was finding it difficult to cope with his job. A severe respiratory tract infection necessitated a home visit by his general practitioner, and he was found to have constricted pupils and severe difficulty in respiration. The patient $N$ confessed that he was taking $120 \mathrm{mg}$ thrice daily.

\section{Discussion}

Although dihydrocodeine is useful as an analgesic, addiction may occur, with severe physical and psychological results on abrupt with- $O$ drawal. Our five cases illustrate the risk of physical dependence on this drug.

Address for reprints: Peter Marks, Thoracic Unit, Westminster Hospital, Horseferry Road, London SW 1 .

1 Eddy, N B, Halbach, H, and Braenden, $\mathrm{O} J$, Bulletin of the World Health Organisation, 1956, 14, 353.

2 Hiller, H J, and Gladtke, E T, Deutsche medizinische Wochenschrift, 1974, ه 28, 1502 .

${ }^{3}$ Peat, M A, and Senguaza, A, Forensic Science, 1977, 9, 21.

(Accepted 21 February 1978)

Westminster Hospital, London SW1P 2AP

PETER MARKS, MRCP, senior research registrar

HASHMAT ASHRAF, FRCS, surgical registrar

T R ROOT, pharmacist 